\title{
Distance-to-target weighting in LCA—A matter of perspective
}

\author{
Marco Muhl $^{1}$ (D) Markus Berger $^{1} \cdot$ Matthias Finkbeiner $^{1}$ \\ Received: 21 June 2020 / Accepted: 27 October 2020 / Published online: 19 November 2020 \\ (C) The Author(s) 2020
}

\begin{abstract}
Purpose Weighting can enable valuable support for decision-makers when interpreting life cycle assessment (LCA) results. Distance-to-target (DtT) weighting is based on the distance of policy (desired) targets to current environmental situations, and recent methodological DtT developments are based on a weighting perspective of a single region or country, considering mainly environmental situations in consuming countries or regions. However, as product supply chains are spread over many countries, this study aims at developing additional weighting approaches (producer regions and worst-case regions) and applying them in a theoretical case study on a global scale.

Methods The current study is carried out to understand the influence of and the effect on weighting results of different countries and regions with their specific environmental policy targets. Based on the existing Ecological Scarcity Method (ESM), ecofactors for the three environmental issues climate change, acidification, and water resources were derived for as many countries as possible. The regional eco-factors were applied in a case study for steel and aluminum considering the three different weighting approaches on different regional scales.

Results and discussion The analysis revealed significant differences in the obtained weighting results as well as strengths and limitations in the applicability of the examined perspectives. Acidification was showed to be highly important with between 80 and $92 \%$ of the aggregated weighting results among the perspectives where water-scarce countries were not involved. Waterscarce countries had a significant influence (75-95\%) when they were part of the examined case study.

Conclusions The developed approaches enable the assessment of global value chains in different producer regions as well as the utilization of the conservative worst-case-regions approach. The approaches can foster future decision-making in LCA contexts while providing country-specific results based on different weighting perspectives in national, regional, and global contexts. However, for a complete implementation of the presented approaches, further data gathering is needed on environmental situations and policy targets in different countries as well as regionalized life cycle data.
\end{abstract}

Keywords LCIA $\cdot$ Distance to target $\cdot$ Weighting $\cdot$ Normalization $\cdot$ Policy targets $\cdot$ Ecological Scarcity Method $\cdot$ Regionalization

\section{Introduction}

Life cycle assessment (LCA) studies inform decision-makers in industry, government, or non-government organizations for strategic planning purposes or prioritization among different product options (ISO 14040 2006). However, many

Communicated by: Michael Z. Hauschild

Marco Muhl

marco.muhl@tu-berlin.de

1 Department of Environmental Technology, Technische Universität Berlin, Straße des 17. Juni 135, 10623 Berlin, Germany comparative LCA studies show contrasting life cycle impact assessment (LCIA) results among the different environmental impacts, making it difficult for decision-makers to determine what the best course of action might be. In this context, weighting can support the decision-making process by considering the previously defined relative importance of the environmental impacts, emissions, or resource uses. Weighting is defined by the ISO standard as "the process of converting indicator results of different impact categories by using numerical factors based on value-choices. It may include aggregation of the weighted indicator results" (ISO 14044 2006). In comparative assertions disclosed to the public, weighting methods shall not be applied (ISO 14044 2006).

Due to the subjectivity of weighting approaches which depend on policy, cultural, or other preferences, no commonly 
accepted consensus method seems to be feasible (Sala and Cerutti 2018). Nonetheless, the ongoing relevance and importance of weighting in LCA (Pizzol et al. 2017; Zanghelini et al. 2018) has resulted in a wide range of existing methods. Currently, both political (e.g., Sala and Cerutti 2018) and corporate (e.g., Ahbe et al. 2018; Vargas-Gonzalez et al. 2019) interest can be observed in the further development of weighting. Different reviews and assessments of existing weighting approaches have been carried out (Huppes and Oers 2011; Huppes et al. 2012; Ahlroth 2014; Finkbeiner et al. 2014; Pizzol et al. 2015, 2017), whereas the most common approaches are panel weighting, monetary weighting, and distance-to-target weighting.

Panel weighting translates preferences, opinions, or decisions of different stakeholders or organizations into weights of impacts using numeric values (Huppes and Oers 2011; Pizzol et al. 2017). Examples of such methods include Eco-indicator 99 (Goedkoop and Spriensma 2001) and ReCiPe (Goedkoop et al. 2013).

Monetary weighting translates impacts into monetary units to determine damage costs or the willingness to pay to prevent damages (Pizzol et al. 2015). Examples of this type of methods include EPS system (Steen et al. 1999a, 1999b), STEPWISE2006 (Weidema 2009), LIME 1-3 (Itsubo et al. 2004, 2012; Inaba and Itsubo 2018), and ECOTAX2002 (Finnveden et al. 2006).

Distance-to-target (DtT) weighting is based on the principle that environmental impacts are weighted according to their distance from the current environmental situation to a defined target.

A selection of DtT approaches which derive their targets from environmental legislation is given in the following:

- The Ecological Scarcity Method (ESM) weights using eco-factors by considering the environmental situation and environmental policy targets of the countries. The method was originally developed for Switzerland (Müller-Wenk (1978)), has been continuously updated, and uses the latest version of eco-factors from 2013 (Frischknecht and Büsser Knöpfel 2013). Based on the Swiss version, eco-factor sets were developed for many countries and regions, such as Norway and Sweden (Lindfors et al. 1995), Japan (Miyazaki et al. 1994; Büsser et al. 2012), Germany (Ahbe et al. 2014), Russia (Grinberg et al. 2012), Thailand (Lecksiwilai et al. 2017), and the European Union (Ahbe et al. 2018; Muhl et al. 2019).

- EDIP 2003 (Hauschild and Wenzel 1998; Hauschild and Potting 2005) developed weighting factors using a Danish perspective. It uses political reduction targets of environmental issues in Denmark.

- For the European Union (EU), another DtT weighting method was developed (Castellani et al. 2016) that takes the policy targets for the year 2020 into consideration. The aggregated weighting factors of this method are calculated on a midpoint level by applying recommended impact categories of the International Life Cycle Data system (ILCD).

In addition to policy-based DtT methods, further methods using targets based on the planetary boundaries concept (Rockström et al. 2009; Steffen et al. 2015) have been published (Tuomisto et al. 2012; Sandin et al. 2015; Bjørn and Hauschild 2015; Vargas-Gonzalez et al. 2019).

The presented distance-to-target weighting approaches were developed for specific countries or regions, reflecting the perspective of the consumer regions, e.g., Switzerland or the European Union. The underlying weighting factors are generally not transferable to other regions due to the different environmental situations and policy framework conditions. Nevertheless, many product value chains are distributed all over the world and potential environmental impacts can occur in many countries. The targets defined by the local environmental policies in these countries can vary greatly from the situations on which existing weighting factor sets are based. Thus, environmental impacts occurring around the world are weighted using the perspective of one region only (Switzerland, EU, etc.).

To understand the specific influence of the considered regions within the weighting process and their associated country- or region-specific environmental situation and target values, a detailed and comparative analysis under consideration of different weighting perspectives is the aim of this study. Therefore, the following objectives were defined:

a. Development of new weighting perspectives besides the existing Consumer-regions approach (I): Producer-regions approach (II), and Worst-case-regions approach (III)

b. Derivation and comparison of eco-factors for all weighting perspectives including as many countries as possible for a selected amount of environmental issues

c. Application of all weighting perspectives: a comparative case study on a global scale for the metals aluminum and steel is to be carried out

\section{Methodology}

All weighting approaches presented in this study are based on the mathematical formula of the Ecological Scarcity Method (ESM) first introduced in Switzerland (Müller-Wenk 1978) and its latest version (Frischknecht and Büsser Knöpfel 2013). It should be noted that the ESM can be adapted to any region in the world, given the existence of data about 
the current environmental situation and the policy targets in the respective countries (Frischknecht and Büsser Knöpfel 2013). Due to the advanced existence of different regional eco-factor sets (see also the introduction) as well as their application potential to other regions, the ESM was chosen for this study. The next subchapters give an overview of the underlying Ecological Scarcity Method as well as their adaptation to the different perspectives. A total of three different weighting perspectives were developed or adapted from existing ones: I. Consumer-regions approach, II. Producerregions approach, and III. Worst-case-regions approach.

\subsection{Ecological Scarcity Method}

The ESM weights elementary flows of substance/resource using eco-factors (Eq. (1)). The calculation of eco-factors consists of four terms: characterization, normalization, weighting, and a constant.

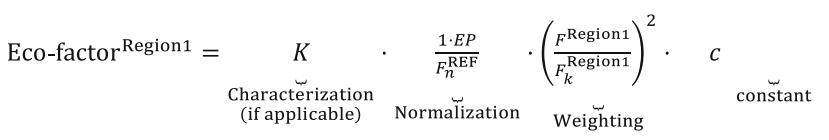

$\begin{array}{ll}K & \begin{array}{l}\text { Characterization factor of an emission or resource } \\ F_{n}^{\text {REF }}\end{array} \\ F^{\text {Region1 }} & \begin{array}{l}\text { Normalization flow: current annual quantity } \\ \text { (emission or consumption), with a defined } \\ \text { reference area as the system boundary }\end{array} \\ F_{k}^{\text {Region1 } 1} & \begin{array}{l}\text { Current flow: current annual quantity (emission or } \\ \text { Critical flow: statutory limit value in a region } 1\end{array} \\ c & \begin{array}{l}\text { Constant (10 } 10^{12} / \text { year): serves to obtain readily } \\ \text { representable numerical quantities }\end{array} \\ \text { EP } & \begin{array}{l}\text { Eco-point: the unit of environmental impact } \\ \text { assessed for a region } 1\end{array}\end{array}$

The characterization as an optional element is applied via specific characterization factors for emissions or resource uses based on reference substances. The normalization uses current environmental flows of a defined reference area to adjust the weighting factor. The weighting factor is based on the distance of actual flows (representing the current annual flow of a reference region) to political targets (critical flows). It uses the squared quotient of the actual flow to the critical flow of a reference region (representing the national targets of the respective environmental policy). The flows always refer to the year of data collection (current flows) and a compliance period or year (critical flows). By squaring the quotient, high exceedances of the critical flow are weighted over-proportionally, whereas significant decreases in the current flow below the critical flows are weighted under-proportionally. For the adjustment of the range of the numerical values and inclusion of the time dimension, all eco-factors are multiplied by an identical constant. The common unit is eco-points (EP) per emitted pollutant or extracted resource.

$\mathrm{EP}=\mathrm{Eco}^{-}$factor $^{\text {Region1 }} \cdot$ Quantity

The eco-points for emissions or resource uses are calculated with the following formula (Eq. (2)). The quantity describes a load of a pollutant, quantity of a resource consumed, or level of a characterized environmental pressure. Finally, the eco-points can be aggregated to a single value to reach a single-score result.

\subsection{Consumer-regions approach}

The consumer-regions approach reflects the original idea of the ESM to weight a wide range of emissions and resource uses by the distance to political targets of a specific country or region using eco-factors. Though the environmental impacts of a specific assessment are not generated in the consumer region, e.g., EU (see Fig. 1), this approach does not consider the environmental situations of other countries and weights their environmental impacts from a consumer-region perspective. In contrast to the other approaches of this paper, only one region (consumer region) is considered for the derivation of all current, critical, and normalization flows, and this is done independently of the location of the product system. The derivation of eco-factors is carried out as described in Section 2.1.

\subsection{Producer-regions approach}

The producer-regions approach reflects a situation in which each country involved in the value chain is considered with its specific resource uses and emissions. These environmental interferences are weighted according to the country-specific and region-specific environmental situation and policy. As Fig. 2 shows using the example of aluminum, all weighting factors within the value chain are considered. It has to be mentioned that regional weighting factors were also derived in the Swiss ESM for the environmental issues water resources and biodiversity loss (Frischknecht and Büsser Knöpfel 2013).

Deviating from Eq. (2) (see Section 2.1), the calculation of eco-points required the following modification:

$$
\mathrm{EP}=\sum_{X=1}^{r}\left(\text { Share }^{\text {Regionx } x} \cdot \text { Eco-factor }^{\text {Regionx } x} \cdot \text { Quantity }\right)
$$

The modification considers the sum of each countryspecific weighting factor multiplied by the relative share of regionalized emissions (produced) or resources (consumed) 
Fig. 1 Schematic illustration of the consumer-regions approach (independent of the product system)

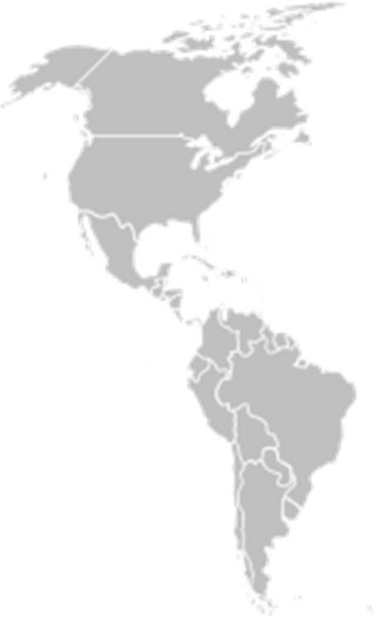

for each region $x$, whereas $r$ is the maximum number of producing regions. For a consistent comparison among the other weighting approaches, the normalization flow of the European Union was used for the calculation of all country-specific ecofactors.

\subsection{Worst-case-regions approach}

The worst-case-regions approach reflects a situation where the weighting factors considered for each environmental issue are based on one country. Unlike the consumer-region approach, different countries can be taken into account when deriving weighting factors. The selection criterion is defined by the strictest (highest) values for the weighting factors of all considered countries for the respective environmental issue. As the example in Fig. 3 shows for the environmental issue of climate change, only weighting factors from Cyprus are used as they have the highest distance-to-target ratio among all considered countries: 5.4 (current flow Cyprus 2014: 7.02
$\mathrm{Mt} \mathrm{CO}_{2}$-eq. (WRI 2020), critical flow Cyprus with target year 2030: $3.03 \mathrm{Mt} \mathrm{CO}_{2}$-eq. (European Union 2015)).

As differences between countries and their weighting factors can vary widely, two distinct options were proposed:

- a - "Global total": This option refers to the strictest value on a global scale. The determined weighting factors with the corresponding country do not necessarily have to be part of the product system (project unspecific). For example: For the environmental issue of climate change, Cyprus had the highest weighting factor with 5.4 (independent of the product system).

- b - "Global project-specific": This option considers only the strictest value of all participating countries within the product system (project-specific). For example: For the environmental issue of climate change, Spain had the highest weighting factor with 3.5 among the steel-producing countries for the European consumption mix (project considered in this study).
Fig. 2 Schematic illustration of the producer-regions approach (example of the product system of aluminum)
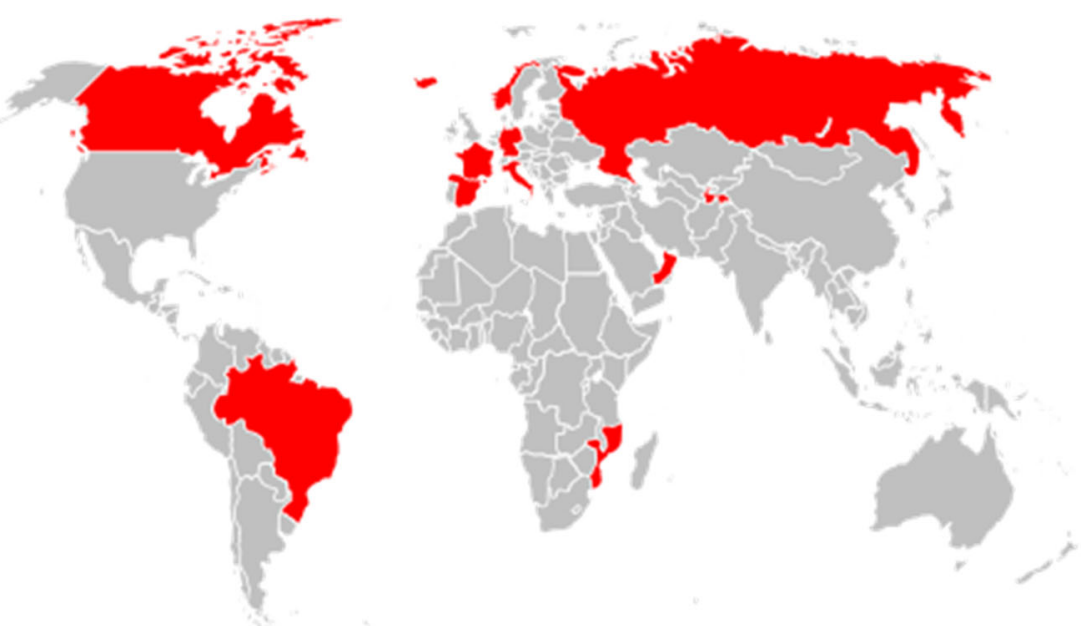
Fig. 3 Schematic illustration of the worst-case-regions approach using the example of Cyprus for the environmental issue of climate change (independent of the product system)
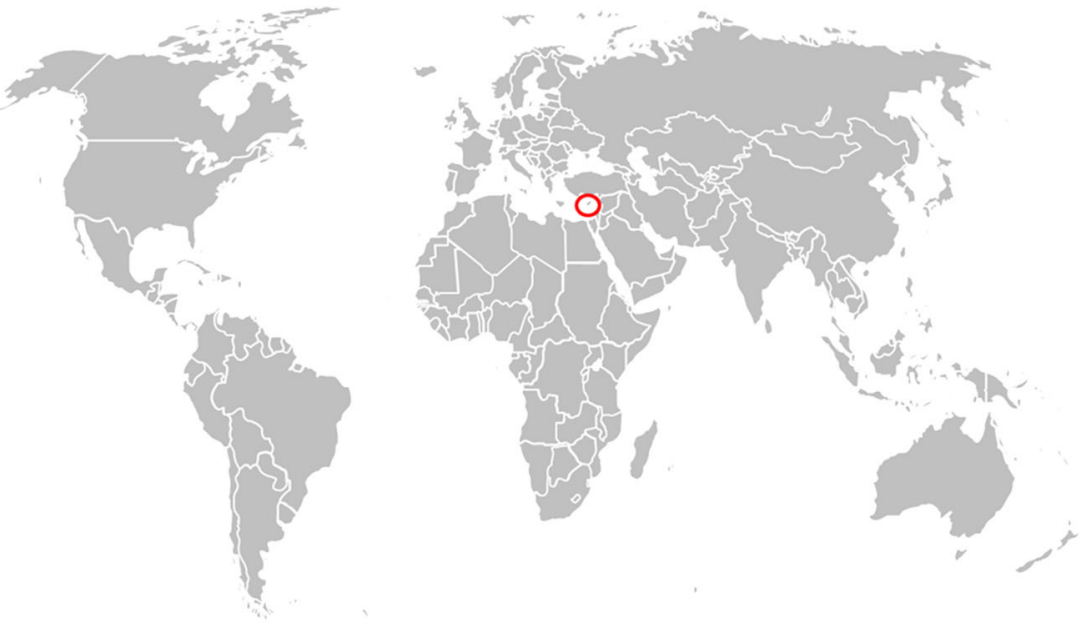

When identifying the country with the strictest weighting factor, only existing policy targets of the respective countries were considered. The worst-case-regions approach has the advantage that assumptions or estimations for missing countries are not necessary due to a basic stock of existing weighting factors. Nevertheless, the maximum number of weighting factors for all existing countries should be considered to assure the highest possible completeness of the weighting factor set and the validity of this approach. For a consistent comparison among the other weighting approaches, the normalization flow of the European Union was used for calculating all country-specific eco-factors.

\subsection{Derivation of eco-factors for weighting approaches}

For the application and a comparative analysis of the presented weighting approaches, it was crucial to collect the current, critical, and normalization flows for as many countries as possible. In a pre-selection process, the environmental issues climate change, water resources, and acidification were selected for a theoretical case study. The selected environmental issues were chosen because they cover environmental impacts at different regional levels: global (climate change), regional (acidification), and local (water resources). For simplification in the context of the study, the substance sulfur dioxide $\left(\mathrm{SO}_{2}\right)$ was selected for the derivation of current and critical flows on behalf of the environmental issue of acidification. This simplification can be justified by the fact that in 2010 , $\mathrm{SO}_{2}$ contributed $50 \%$ to the environmental impact category acidification on a global level (Oita et al. 2016; Crenna et al. 2019). In this context, it has to be mentioned that deriving weighting factors on an impact category level covering all acidifying substances would have been desirable but was not feasible due to the lack of policy targets (e.g., expressed in $\mathrm{SO}_{2}$ equivalents).
Principles governing the derivation of eco-factors were maintained, e.g., the selection of the strictest eco-factor, if several options were available. To derive the eco-factors, the following steps were carried out (valid for all presented approaches):

1. Identification of current and normalization flows. Flows were determined by review and examination of existing data sources from various databases (data reported in S1), e.g., the Centre on Emission Inventories and Projections (CEIP/EMEP 2020), World Resources Institute (WRI 2020), and Food and Agriculture Organization of the United Nations (FAO 2020).

2. Identification of critical flows. Flows were derived by reviewing existing policy targets (e.g., UNFCCC 2020; EP 2016). Additionally, in the case of water resources, non-binding targets could be derived from international protection targets (OECD 2003) (data reported in S1). The selection criterion was always the strictest target value, which ensured a conservative approach for the calculation of eco-factors.

3. Finalization of eco-factors. Using the equation presented in Section 2.1, eco-factors were calculated for the environmental issues climate change, water resources, and acidification.

\subsection{Case study}

A theoretical case study of the metal products with the highest production amounts was conducted to demonstrate the applicability for the three weighting approaches in a comparative analysis. Aluminum and steel complied with the requirements regarding country-specific production data on a global scale as well as existing LCIA data. Moreover, the selected metals account together for more than $90 \%$ of annual finished metal production by weight at a global level (OECD 2017). 
The product system contained the metal products of aluminum and steel (cradle to gate). The functional unit was one metal product with assumed reference flows of $1 \mathrm{~kg}$ aluminum ingot and $1 \mathrm{~kg}$ steel hot-rolled coil. LCIA data for the environmental issues climate change, acidification, and water resources was derived from recent publications of the International Aluminium Institute (IAI 2018) and the World Steel Association (Worldsteel 2018) (see Table 1). The data considered global production mixes based on survey data from the member companies of the organizations as well as companies participating in the surveys.

For the application of the producer-regions approach (Section 2.2), geographically explicit LCA data is required, which is available in existing databases only to a limited extent. In a top-down approach (Berger et al. 2012), the total water use and emission flows of the datasets were allocated to the producer countries based on the European consumption mixes. The European consumption mixes included countries from domestic production (EU) as well as imports from outside the EU. For this, country-specific production data from the United States Geological Survey (U.S. Geological Survey 2020), the World Steel Association (Worldsteel 2016), and the European Aluminium Association (European Aluminium 2018) was used. Based on this top-down approach, the geographically unspecific inventories of the global datasets were allocated to 29 countries (for aluminum) and 25 countries (for steel) (see Fig. 4). Details regarding the data allocation to the producer countries can be found in the supplementary material.

Table 1 Overview of the LCIA data considered in this study for steel hot-rolled coil (global) and aluminum ingot mix (global) based survey data from the member companies of the organizations as well as companies participating in the surveys (IAI 2018; Worldsteel 2018)

\begin{tabular}{|c|c|c|}
\hline Environmental issues & $\begin{array}{l}\text { Steel hot-rolled coil } \\
\text { (global) (Worldsteel } \\
\text { 2018) }\end{array}$ & $\begin{array}{l}\text { Aluminum ingot } \\
\operatorname{mix} \text { (global) (IAI } \\
2018 \text { ) }\end{array}$ \\
\hline $\begin{array}{l}\text { Climate change (CML2001 - } \\
\text { Jan. 2016, global warming } \\
\text { potential (GWP } 100 \text { years)) } \\
\text { [kg CO2 eq. }]\end{array}$ & 23 & 17 \\
\hline $\begin{array}{l}\text { Acidification (CML2001 - } \\
\text { Jan. 2016, acidification po- } \\
\text { tential (AP)) [kg SO2 eq.] }\end{array}$ & 0.01 & 0.09 \\
\hline $\begin{array}{l}\text { Water resources (blue water } \\
\text { consumption) })^{1}[\mathrm{~kg}]\end{array}$ & 8.8 & 88.6 \\
\hline \multicolumn{3}{|c|}{$\begin{array}{l}{ }^{1} \text { Blue water consumption is defined by (Pieper et al. } 2018 \text { ): blue wate } \\
\text { consumption = fresh water + ground water + lake water (incl. turbined) + } \\
\text { river water (incl. turbined) + water (fossil groundwater) - cooling water to } \\
\text { lake - cooling water to river - processed water to groundwater }- \text { proc- }- \\
\text { essed water to lake }- \text { processed water to river - turbined water to lake - } \\
\text { turbined water to river }\end{array}$} \\
\hline
\end{tabular}

\section{Results and discussion}

The application of the three presented weighting approaches resulted in the derivation of eco-factors for the environmental issues climate change, acidification, and water resources. As shown in Table 2, each approach reflects a different aim and therefore a different amount of considered countries with their respective eco-factors. Details regarding the derivation of ecofactors and the underlying data can be found in the supplementary material.

Given the nature of the consumer-regions perspective, only one eco-factor for each environmental issue was derived. Theoretically, the user can select the region, but in this study, the European Union was chosen. The worst-case-regions perspective requires three eco-factors for each environmental issue, one for the strictest value on a global scale (project unspecific) and the strictest values of all steel- and aluminumproducing countries within the project, which results in two additional eco-factors for this study.

The aim of the producer-regions perspective was to derive eco-factors for as many countries involved in the supply chain as possible. In the case of water resources, the best data availability among the environmental issues existed which resulted in the highest number of eco-factors (164), whereas for climate change (66) and acidification (56), fewer countries were considered mainly due to missing political targets at a country level. Several obstacles arose for the producer-regions approach due to the following reasons:

1. Lack of data. For several countries, identifying current and/or critical flows was not possible, as this method relied on publically available databases. For a future integration of these substances, additional data collection has to be carried out.

2. Definition of targets. When deriving country-specific ecofactors, only absolute or relative emission reductions were considered. In the case of climate change, many countries defined their pledges (targets) as a reduction of carbon intensity related to the gross domestic product (GDP) or in comparison to business as usual (BAU) scenarios (UNFCCC 2020). These targets could not be used for numerical values as they rely on unknown economical data of future developments.

3. Lack of target values. In the absence of target values for certain countries, it was assumed that the current flow is equal to the critical flow. This assured the consideration of minimum criticality for the countries considered in the case study.

\subsection{Analysis of weighting approaches applied to the case study}

The different weighting approaches were applied in a case study to aluminum ingot and steel hot-rolled coil with their 
Fig. 4 Percentage country allocation for steel hot-rolled coil and aluminum ingot in the European consumption mixes

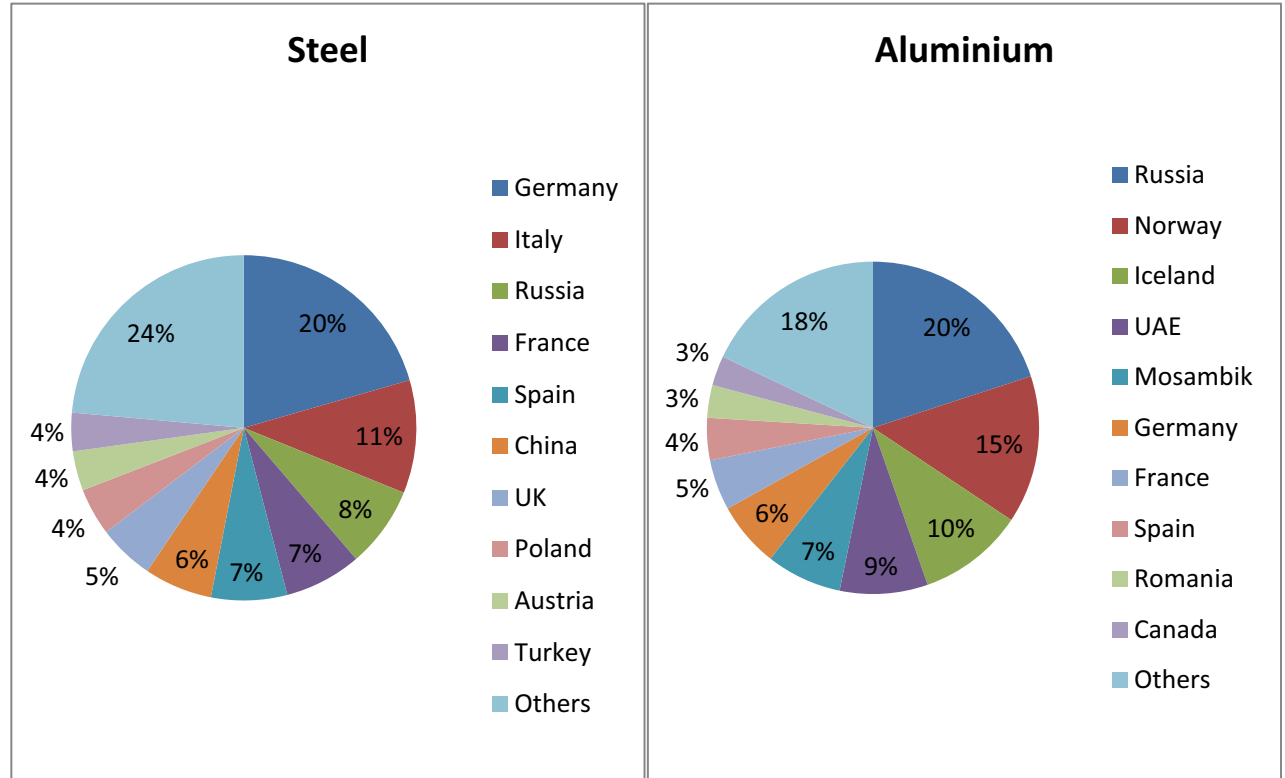

European consumption mixes. For the consumer-regions and worst-case-regions perspective, calculating eco-points was a straightforward task (see Eq. (2)). In contrast, applying the producer-regions perspective first required allocating geographically unspecific LCI flows to specific countries based on the European consumption mixes. In the second step, the now regionalized inventory data was multiplied with the corresponding country-specific eco-factors and the resultant ecopoints were summed up (see Eq. (3)).

Figure 5 shows the relative importance of the environmental issues in the aggregated weighting results for each weighting approach. For each metal product, the share of the weighting results in percentages is shown, resulting in a sum of $100 \%$. Only relative numbers are shown as the case study was not aiming for a classical comparison of two products or components with a consistent functional unit. More detailed information is also provided in the supplementary material.

In the consumer-regions approach for the European Union, for both metal products, acidification made the greatest contribution (83\% and 92\%) to the aggregated eco-points. Climate change exhibited lower importance (16\% and $8 \%$ ), whereas water resources only showed a marginal influence.
The high contribution of acidification can be explained with the relatively high eco-factor for $\mathrm{SO}_{2}\left(0.9 \mathrm{EP} / \mathrm{g} \mathrm{SO}_{2}\right)$ in comparison to the eco-factor for $\mathrm{CO}_{2}$ equivalents $(0.0004 \mathrm{EP} / \mathrm{g}$ $\mathrm{CO}_{2}$-eq.) which were multiplied with the LCIA data (see Table 1). For the European Union, the $\mathrm{SO}_{2}$-reduction targets were defined with $-79 \%$ until 2030 in comparison to 2005 (EP 2016) which resulted in a stricter target as for greenhouse gas emissions ( $-40 \%$ until 2030 compared to the 1990 level).

The second weighting approach (producer regions) revealed similar results for steel ( $80 \%$ acidification, $19 \%$ climate change). A detailed analysis regarding the contribution of the producing countries to the overall weighting results is given in Section 3.2.

In contrast, substantial differences appeared for aluminum regarding the water resources with a high share $(83 \%)$ of the aggregated weighting results. The reason was the high contribution of the United Arab Emirates (UAE), which alone was responsible for $99.8 \% \mathrm{EP}$ for the environmental issue water resources. This can be explained because the UAE is the second most water-scarce country in this study after Kuwait with a weighting factor of 7293 . The shares of acidification (15\%) and climate change (2\%) were thus significantly lower than in the consumer-regions approach.
Table 2 Number of countries/ regions considered in the derivation of eco-factors for environmental issues climate change, acidification, and water resources

\begin{tabular}{|c|c|c|c|}
\hline \multirow[t]{2}{*}{ Environmental issues } & \multicolumn{3}{|c|}{ Number of countries/regions considered with country-specific eco-factors } \\
\hline & $\begin{array}{l}\text { a) Consumer-regions } \\
\text { approach }\end{array}$ & $\begin{array}{l}\text { b) Producer-regions } \\
\text { approach }\end{array}$ & $\begin{array}{l}\text { c) Worst-case-regions } \\
\text { approach }\end{array}$ \\
\hline Climate change & 1 & 66 & 3 \\
\hline Acidification & 1 & 56 & 3 \\
\hline Water resources & 1 & 164 & 3 \\
\hline
\end{tabular}


Fig. 5 Relative shares (in \%) of environmental issues of applied weighting approaches (I. Consumer regions, II. Producer regions, III. Worst case regions (a: global total, b: global projectspecific)) with EU28 normalization flow for aluminum ingot mix and steel hot-rolled coil

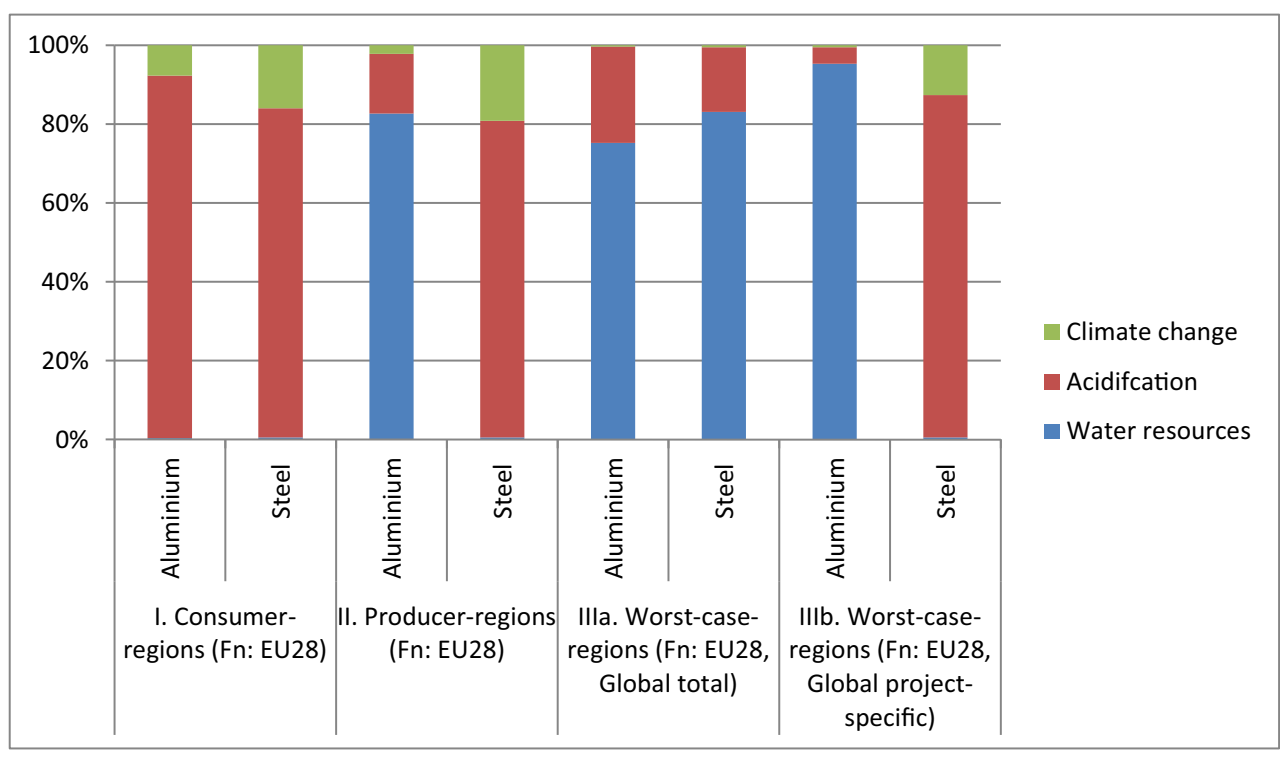

A similar situation resulted from the worst-case-regions approach (IIIa), where the eco-points were calculated with the strictest weighting factor of Kuwait for water resources. The contribution of water resources to the aggregated ecopoints was between $75 \%$ for aluminum and $83 \%$ for steel. In the IIIb approach for aluminum, the eco-points of water resources had the highest share (95\%) in comparison to all other approaches. This can be explained by the fact that the UAE has a high weighting factor and the fact that the other countries considered for each environmental issue in this study had a comparatively lower weighting factor (acidification strictest weighting factor: 3.5 for UK, climate change strictest weighting factor: 4.1 for Brazil). In the absence of extreme water-scarce countries in the producing countries, Hungary had the strictest project-specific weighting factor (5.7). As a result, acidification had the dominant share $(87 \%)$ of the weighting results in the worst-regions IIIb approach for steel.

In the worst-case-regions approach, climate change had a low relative importance among all aggregated weighting results, both for aluminum and steel. One explanation is the lower range of weighting factors. The example of Cyprus with the highest weighting factor of 5.4 among all countries showed that the distance of the current situation to the target values seemed to be lower than, for example, in the case of water resources (strictest weighting factor Kuwait with 10,764.1) or acidification (strictest weighting factor Cyprus with 38.2).

\subsection{Producer-regions approach-influence of coun- tries to the aggregated weighting results}

The aim of the producer-regions approach was to consider each regionalized emission (produced) or resource (consumed) with their corresponding country-specific weighting factor. To get a better understanding of each country's influence, the share of each country to the overall weighting results for each environmental issue is displayed in Fig. 6. The consideration of countryspecific weighting factors showed that countries with a comparatively high weighting factor increased their relative contribution in comparison to the shares of the countries in the European consumption mixes (Fig. 4). For example, in the case of steel and acidification, Germany and the UK with relatively high weighting factors of 2.5 and 3.5 were responsible for $42 \%$ of aggregated eco-points, but contributed only $20 \%$ (Germany) and 5\% (UK) to the European production mix. In contrast, countries with comparatively low weighting factors decreased their importance to the overall weighting results. This was the case for water resources, for example, where Russia only had marginal contributions to the overall weighting results but was one of the major producers in the European production mix for steel (8\%) and aluminum $(20 \%)$.

Nonetheless, challenges in the spatial resolution of LCIA data also occurred. The allocation of producing countries from the global production mixes to the European consumption mixes for steel and aluminum was based on the top-down approach (see Section 2.6). In the simplification of this study, it was assumed that the distribution of the producing countries was equivalent to the distribution of the inventories. That is, an equal water use and emission intensity in all producing countries was assumed. Therefore, distortions can occur as LCIA results of different regional production mixes can vary significantly from the global production mixes. For the European aluminum producers, the International Aluminium Institute reported a GWP of only $41 \%$ in comparison to the global production mix, whereas China, as the largest producing region with $56 \%$ of the global production in 2017 (IAI 2018), showed for the regional Chinese scenario a GWP of $118 \%$ in comparison to the global production mix (IAI 2017, 2018). In the case study (aluminum), Norway and Iceland 


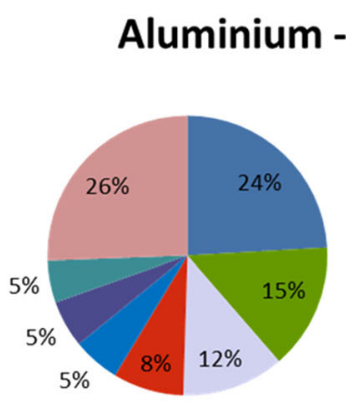

- Norway

- Iceland

russia

- Spain

- Germany

- France

- UAE

- Others

Steel - CC

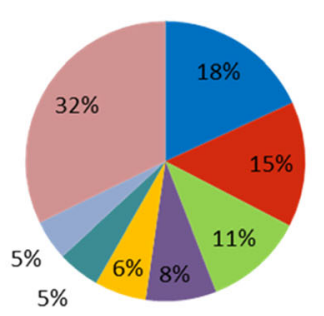

Aluminium - Acidification

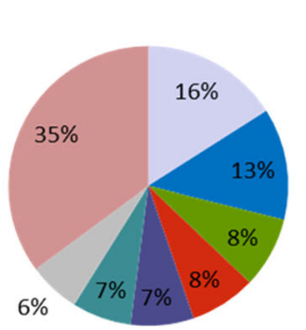

nussia

aermany

EIceland

- Spain

- France

- UAE

Elovakia

n Others
Aluminium - Water

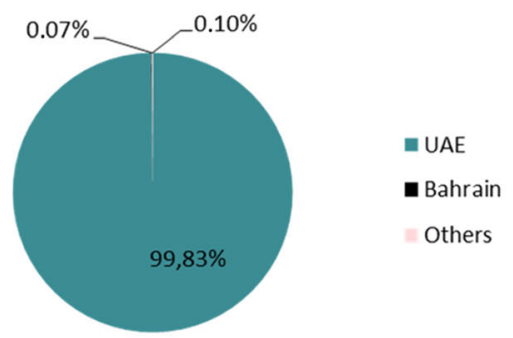

Steel - Acidification

- Germany

- Spain

- Italy

- France

In Austria

- Poland

nussia

- Others

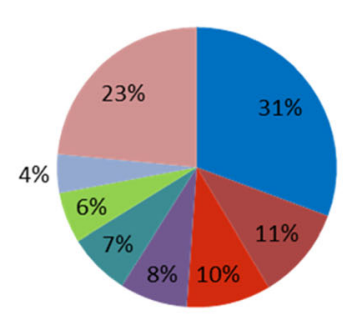

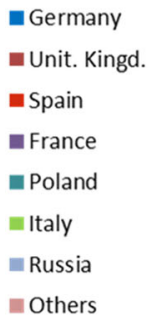

Steel -Water
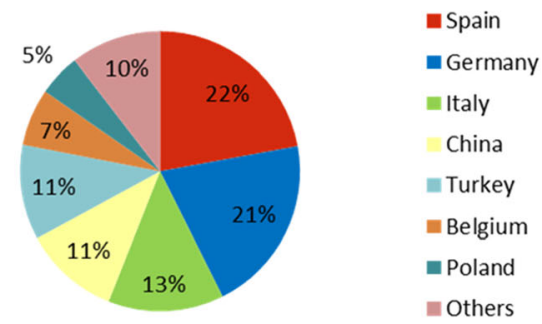

Fig. 6 Producer-regions perspective — relatives shares (in \%) of countries with corresponding eco-points for steel hot-rolled coil and aluminum ingot for the environmental issues (climate change (CC), acidification, and water resources)

were responsible for $25 \%$ of the European consumption mixes but contributed to $39 \%$ of the eco-points for the environmental issue of climate change. This can be explained by the high DtT ratio of these countries (weighting factor Norway: 3.0, weighting factor Iceland: 2.5 ). But it must be kept in mind that the aluminum producers in these two countries have a high share of renewable energies in the electrolysis process and, therefore, a lower share for the indicator GWP of the global production mix than considered in this study (IAI 2017, 2018). A similar situation occurred for aluminum and the environmental issue water resources in the case of the producing countries of the Gulf Cooperation Council (GCC). According to the International Aluminium Institute, aluminum production in the GCC countries had only $11 \%$ of the Water Scarcity Footprint (WSFP) in comparison to the global production mix (IAI 2017). The consideration of country-specific LCIA data was not possible, as in the current data sets they were available in an aggregated form only. Although progress has already been made in the regionalization of LCI data in existing databases, e.g., water and land use (thinkstep 2019). For a complete implementation of the producer-regions approach, further data availability of regionalized LCI as well as LCIA data is required. Current publications (Mutel et al. 2019; Pfister et al. 2020) presented recommendations and challenges of regionalized LCA. In practice, many regionalized methods are still underutilized due to the lack of regionalized data (Pfister et al. 2020). The need for a wider provision of regionalized LCI data is therefore crucial to enhance the operability of the approach and the informative value of the obtained weighting results.

\subsection{Added values and limitations of the presented weighting approaches}

The study applied the existing consumer-regions approach while also developing new perspectives, which had been missing so far. Nonetheless, all perspectives showed strengths and limitations which are compared in the following:

- Consumer-regions approach: Besides the availability and the possible application of extensive eco-factor sets developed in the past (e.g., Switzerland (Frischknecht and Büsser Knöpfel 2013), Germany (Ahbe et al. 2014), Russia (Grinberg et al. 2012), Thailand (Lecksiwilai et al. 2017), and European Union (Ahbe et al. 2018; Muhl et al. 2019)), the LCA practitioner can only choose among a limited amount of regional eco-factor sets. Aspects like the integration of a broad amount of producing countries are not considered. Beneficial from a user perspective is the immediate application for many regions, whereas the development of global eco-factors does not seem realistic in the short and medium term due to missing policy targets at a global level. In this context, to mention are the UN Sustainable Development Goals (SDGs) (United Nations 2015) which show interlinkages to environmental impact categories and could be a potential source for the derivation of targets in the future. So far the integration of SDGs into environmental assessments with a wide coverage of environmental impacts is still on a conceptional or screening stage (Weidema et al. 2020; Sala et al. 2020; Kørnøv et al. 2020). 
- Producer-regions approach: In comparison to the other approaches, a wide range of countries can be considered in the weighting process. It most comprehensively reflects the global value chains distributed over many countries in the world with their specific environmental situations and policy targets. However, applying this approach places high requirements on regionalized data, both for inventory and weighting factors. At the moment, therefore, it can only be used with the help of simplifications (e.g., topdown approach for regionalized data, lack of critical flows). Taking into account current limitations, the producer-regions approach appears to be the most beneficial option in the medium to long term for a regionalized application on a global scale, as environmental impacts in the country of origin are represented to the greatest extent.

- Worst-case-regions approach: Due to high data availability in terms of existing weighting factors for different countries and regions, this approach can be applied in the short term and medium term on a global scale. Nonetheless, it is considered to be the most conservative approach, which can lead to an overachievement of regional environmental targets. It has to be kept in mind that the strictest weighting factors can be a result of either the most ambitious targets or high current flows in comparison to the targets. Furthermore, large distortions in the weighting results can occur, as observed in this study for water resources. For decision-makers, the worstcase-regions approach can be used as an additional tool to consider the possible development of stricter targets (e.g., in a sensitivity analysis). Nonetheless, transparent documentation of the underlying targets and methodology is essential for a reasonable application.

Besides the challenges of each weighting approach, there were also difficulties common to all approaches.

Normalization is an essential part in the weighting of LCA results and a highly controversial topic due to its significant influences on the weighting results (Kägi et al. 2016; Pizzol et al. 2017; Prado et al. 2019). In order to have a consistent normalization procedure among the presented weighting approaches, a region should be selected that is as representative as possible. It should also have the maximum possible coverage of different countries to avoid the risk of inconsistency between the different regions (Verones et al. 2017). In this study, the European Union was selected for the normalization flows to allow a consistent comparison. In the future, global normalization factors (Crenna et al. 2019) could also be applied for the producer-regions and worst-case-regions approaches.

In the presented approaches, environmental issues were weighted on an impact category level only. For simplification reasons in the context of the study, the substance sulfur dioxide (SO2) was selected as a "screening emission" for the environmental issue of acidification. This simplification was supported by the fact that $\mathrm{SO} 2$ was the major contributor to the environmental impact category of acidification on a global level (Crenna et al. 2019; Oita et al. 2016) (see Section 2.5). Nonetheless, for a complete assessment, all acidifying substances have to be included in future developments. The need for this assumption showed the current weakness of this approach for the derivation of eco-factors for all impact categories or as many emissions and resource uses as possible. The lack of data, especially for the critical flows, remains an important challenge in the future enhancement of weighting approaches. Where possible, future developments could consider global target values (e.g., ozone-depleting substances (UNEP 2016)) for the derivation of global eco-factors.

Nonetheless, the presented approaches are based on an inventory level for the ESM (Huppes and Oers 2011), which can provide weighting factors besides the impact category level. So far, a complete integration of all LCA-relevant flows into midpoint weighting is not possible, due to missing data on critical flows (Castellani et al. 2016; Muhl et al. 2019). In the absence of policy targets on an impact category level, substance-specific weighting factors should be derived.

\section{Conclusions}

Contrasting results of life cycle assessments are ambiguous and show tradeoffs among different environmental impacts that do not allow a straight forward conclusion. In this context, weighting in LCA can have an important role in the decisionmaking process. Distance-to-target (DtT) weighting methods can derive their weighting factors from democratically legitimized policy targets of the country to be considered, which can strengthen the acceptance of the method among different stakeholders in comparison to other methods.

Conventional DtT weighting methods are focused on specific regions or countries, taking their environmental situation as well as their national policy targets into consideration (consumer regions). Problems like the transferability of the underlying weighting factors to other regions for the assessment of globally distributed value chains remain unresolved when applying only the consumer-regions perspective.

In this context, this study developed two approaches to compare to the existing consumer-regions approach: the producer-regions and worst-case-regions approaches. The producer-regions approach considers the complexity of globally distributed value chains over many countries with their specific environmental situations and specific policy targets, whereas the worst-case-regions approach can be helpful for decision-makers to consider the possible development of stricter targets (e.g., in a sensitivity analysis). Eco-factors were derived for as many countries as possible for the selected environmental issues climate change (66), acidification (56), and water resources (164). All weighting perspectives were applied in a theoretical case study for aluminum and steel. 
The consideration of water-scarce countries in the producer-regions and worst-case-regions approaches showed a significant change in the weighting results compared to the consumer-regions approach. The bottleneck for a regionalized weighting approach resulted in the lack of data availability for critical and current flows of all countries. Furthermore, assumptions were needed to allocate geographically unspecific LCI flows to the producing countries, which highlights the need for regionalized data for emissions and resource uses in LCA databases. Alternatively, some critical flows may be derived from the UN Sustainable Development Goals although at the moment approaches for the integration into the LCA framework are still under development (Weidema et al. 2020; Sala et al. 2020; Kørnøv et al. 2020). Such additional information, as well as further methodological developments (e.g., hybrid approaches), could substantially improve the informative value of future assessments.

The different weighting approaches of this study consider legitimized political targets only and, thus, can support LCAbased decision-making. The approaches can be applied in parallel as well as independently from each other depending on the user's focus. Nonetheless, for a careful interpretation of the results as well as the understanding of the different approaches in the application for complex value chains, transparent documentation of the underlying approaches is essential.

Supplementary Information The online version contains supplementary material available at https://doi.org/10.1007/s11367-020-01837-2.

Acknowledgements Open Access funding enabled and organized by Projekt DEAL.

Open Access This article is licensed under a Creative Commons Attribution 4.0 International License, which permits use, sharing, adaptation, distribution and reproduction in any medium or format, as long as you give appropriate credit to the original author(s) and the source, provide a link to the Creative Commons licence, and indicate if changes were made. The images or other third party material in this article are included in the article's Creative Commons licence, unless indicated otherwise in a credit line to the material. If material is not included in the article's Creative Commons licence and your intended use is not permitted by statutory regulation or exceeds the permitted use, you will need to obtain permission directly from the copyright holder. To view a copy of this licence, visit http://creativecommons.org/licenses/by/4.0/.

\section{References}

Ahbe S, Schebek L, Jansky N, et al (2014) Methode der ökologischen Knappheit für Deutschland - Eine Initiative der Volkswagen AG. Logos Verlag, Berlin

Ahbe S, Weihofen S, Wellge S (2018) The Ecological Scarcity Method for the European Union. Springer Fachmedien Wiesbaden, Wiesbaden

Ahlroth S (2014) The use of valuation and weighting sets in environmental impact assessment. Resour Conserv Recycl 85:34-41. https://doi. org/10.1016/j.resconrec.2013.11.012
Berger M, Warsen J, Krinke S, Bach V, Finkbeiner M (2012) Water footprint of European cars: potential impacts of water consumption along automobile life cycles. Environ Sci Technol 46:4091-4099. https://doi.org/10.1021/es2040043

Bjørn A, Hauschild MZ (2015) Introducing carrying capacity-based normalisation in LCA: framework and development of references at midpoint level. Int J Life Cycle Assess 20:1005-1018. https://doi. org/10.1007/s11367-015-0899-2

Büsser S, Frischknecht R, Hayashi K, Kono J (2012) Ecological Scarcity Japan. ESU-services Ltd., Uster, Switzerland

Castellani V, Benini L, Sala S, Pant R (2016) A distance-to-target weighting method for Europe 2020. Int J Life Cycle Assess 21: 1159-1169. https://doi.org/10.1007/s11367-016-1079-8

CEIP/EMEP (2020) ceip (Centre on Emission Inventories and Projections), EMEP (European Monitoring and Evaluation Programme). https://www.ceip.at/. Accessed 6 Apr 2020

Crenna E, Secchi M, Benini L, Sala S (2019) Global environmental impacts: data sources and methodological choices for calculating normalization factors for LCA. Int J Life Cycle Assess 24:1-27. https://doi.org/10.1007/s11367-019-01604-y

EP (2016) Directive 2016/2284 of the European Parliament and of the Council of 14 December 2016 on the reduction of national emissions of certain atmospheric pollutants, amending Directive 2003/35/EC and repealing Directive 2001/81/EC (text with EEA relevance). Off J Eur Union:1-31

European Aluminium (2018) Environmental Profile report - Life-Cycle inventory data for aluminium production and transformation processes in Europe. Brussels, Belgium

European Union (2015) Intended Nationally Determined Contribution of the EU and its Member States. https://ec.europa.eu/clima/sites/ clima/files/docs/2015030601 eu indc en.pdf. Accessed 11 Jun 2020

FAO (2020) AQUASTAT database. Food and Agriculture Organization of the United Nations. http://www.fao.org/nr/water/aquastat/data/ query/index.html?lang=en. Accessed 12 Jun 2017

Finkbeiner M, Ackermann R, Bach V et al (2014) Challenges in life cycle assessment: an overview of current gaps and research needs. Springer, Dordrecht, pp 207-258

Finnveden G, Eldh P, Johansson J (2006) Special Issue Honouring Helias A. Udo de Haes: LCA methodology weighting in LCA based on ecotaxes development of a mid-point method and experiences from case studies. Paris Int J LCA 11:81-88. https://doi.org/10.1065/lca2006.04.015

Frischknecht R, Büsser Knöpfel S (2013) Swiss Eco-Factors 2013 according to the Ecological Scarcity Method. Methodological fundamentals and their application in Switzerland. Environmental Studies no. 1330. Federal Office for the Environment, Bern

Goedkoop M, Spriensma R (2001) The eco-indicator 99 a damage oriented method for life cycle impact assessment. Methodology Report. B.V, Amersfoort

Goedkoop M, Heijungs R, Huijbregts M, et al. (2013) ReCiPe 2008. A LCIA method which comprises harmonised category indicators at the midpoint and the endpoint level. First edition (version 1.08). Report I: characterisation

Grinberg M, Ackermann R, Finkbeiner M (2012) Ecological scarcity method: Adaptation and implementation for different countries. Environ Clim Technol 10:9-15. doi: 10.2478/v10145-012-0019-5

Hauschild M, Potting J (2005) Spatial differentiation in life cycle impact assessment - the EDIP2003 methodology. Danish Ministry of Environment, Environmental Protection Agency, Copenhagen

Hauschild M, Wenzel H (1998) Environmental assessment of products: scientific background, vol 2. Chapman \& Hall, United Kingdom/ Kluwer Academic Publishers, Hingham

Huppes G, Van Oers L (2011) Background review of existing weighting approaches in life cycle impact assessment (LCIA). Publications Office of the European Union, Luxembourg. 88 pp. https://doi.org/ $10.2788 / 88828$ 
Huppes G, Van Oers L, Pretato U, Pennington DW (2012) Weighting environmental effects: analytic survey with operational evaluation methods and a meta-method. Int J Life Cycle Assess 17:876-891. https://doi.org/10.1007/s11367-012-0415-x

IAI (2017) Life Cycle Inventory and Environmental Metrics Report for the Primary Aluminium Industry - 2015 Data. https://www.worldaluminium.org/media/filer_public/2018/02/19/ lca report 2015 final 26 june 2017.pdf. Accessed 7 Apr 2020

IAI (2018) Adddendum to the Life Cycle Inventory and Environmental Metrics Report for the Primary Aluminium Industry - 2015 Data. https://www.world-aluminium.org/media/filer_public/2018/09/20/ addendum_to_lca_report_2015_aug_2018.pdf. Accessed 7 Apr 2020

Inaba A, Itsubo N (2018) Preface. Int J Life Cycle Assess 23:2271-2275. doi: 10.1007/s11367-018-1545-6

ISO 14040 (2006) ISO 14040 - environmental management-life cycle assessment - principles and framework. International Standard Organization, Geneva

ISO 14044 (2006) ISO 14044 - environmental management-life cycle assessment - requirements and guidelines. International Standard Organization, Geneva

Itsubo N, Sakagami M, Washida T, Kokubu K, Inaba A (2004) Weighting across safeguard subjects for LCIA through the application of conjoint analysis. Int J Life Cycle Assess 9:196-205. https:// doi.org/10.1007/BF02994194

Itsubo N, Sakagami M, Kuriyama K, Inaba A (2012) Statistical analysis for the development of national average weighting factorsvisualization of the variability between each individual's environmental thoughts. Int J Life Cycle Assess 17:488-498. https://doi. org/10.1007/s11367-012-0379-x

Kägi T, Dinkel F, Frischknecht R, Humbert S., Lindberg J., de Mester S., Ponsioen T., Sala S., Schenker U.W. (2016) Session "midpoint, endpoint or single score for decision-making?"-SETAC Europe 25th Annual Meeting, May 5th, 2015. Int J Life Cycle Assess 21: 129-132. doi: https://doi.org/10.1007/s11367-015-0998-0

Kørnøv L, Lyhne I, Davila JG (2020) Linking the UN SDGs and environmental assessment: towards a conceptual framework. Environ Impact Assess Rev 85:106463. https://doi.org/10.1016/j.eiar.2020.106463

Lindfors LG, Kim Christiansen K, Hoffman L, et al (1995) Nordic Guidelines on Life-Cycle Assessment. Nordic Council of Ministers. Århus

Miyazaki N, Siegenthaler C, Schoenbaum T, Azuma K (1994) Japan Environmental Policy Priorities Index (JEPIX) - Calculation of Ecofactors for Japan: Method for Environmental Accounting based on the EcoScarcity Principle. 7. International Christian University Social Science Research Institute, Tokyo

Muhl M, Berger M, Finkbeiner M (2019) Development of eco-factors for the European Union based on the Ecological Scarcity Method. Int J Life Cycle Assess 24:1701-1714. https://doi.org/10.1007/s11367018-1577-y

Müller-Wenk R (1978) Die ökologische Buchhaltung: Ein Informationsund Steuerungsinstrument für umweltkonforme Unternehmenspolitik. Campus-Verlag, Frankfurt

Mutel C, Liao X, Patouillard L, Bare J, Fantke P, Frischknecht R, Hauschild M, Jolliet O, Maia de Souza D, Laurent A, Pfister S, Verones F (2019) Overview and recommendations for regionalized life cycle impact assessment. Int J Life Cycle Assess 24:856-865. https://doi.org/10.1007/s11367-018-1539-4

Lecksiwilai N, Gheewala SH, Silalertruksa T, Mungkalasiri J (2017) LCA of biofuels in Thailand using Thai Ecological Scarcity method. Journal of Cleaner Production 142:1183-1191

OECD (2003) Environmental performance reviews: water; performance and challenges in OECD countries. Organisation for Economic Cooperation and Development, OECD, Paris

OECD (2017) Working party on resource productivity and waste: mapping support for primary and secondary metal production
Oita A, Malik A, Kanemoto K, Geschke A, Nishijima S, Lenzen M (2016) Substantial nitrogen pollution embedded in international trade. Nat Geosci 9:111-115. https://doi.org/10.1038/ngeo2635

Pfister S, Oberschelp C, Sonderegger T (2020) Regionalized LCA in practice: the need for a universal shapefile to match LCI and LCIA. Int J Life Cycle Assess 25:1867-1871

Pieper M, Kupfer T, Thylmann D, Bos U (2018) Introduction to water assessment in $\mathrm{GaBi}$

Pizzol M, Weidema B, Brandão M, Osset P (2015) Monetary valuation in life cycle assessment: a review. J Clean Prod 86:170-179. https:// doi.org/10.1016/j.jclepro.2014.08.007

Pizzol M, Laurent A, Sala S, Weidema B, Verones F, Koffler C (2017) Normalisation and weighting in life cycle assessment: quo vadis? Int J Life Cycle Assess 22:853-866. https://doi.org/10.1007/s11367016-1199-1

Prado V, Cinelli M, Ter Haar SF et al (2019) Sensitivity to weighting in life cycle impact assessment (LCIA). Int J Life Cycle Assess:1-14. https://doi.org/10.1007/s11367-019-01718-3

Rockström J, Steffen W, Noone K, Persson Å, Chapin FS III, Lambin EF, Lenton TM, Scheffer M, Folke C, Schellnhuber HJ, Nykvist B, de Wit CA, Hughes T, van der Leeuw S, Rodhe H, Sörlin S, Snyder PK, Costanza R, Svedin U, Falkenmark M, Karlberg L, Corell RW, Fabry VJ, Hansen J, Walker B, Liverman D, Richardson K, Crutzen P, Foley JA (2009) A safe operating space for humanity. Nature 461: 472-475. https://doi.org/10.1038/461472a

Sala S, Cerutti AK (2018) Development of a weighting approach for the environmental footprint. doi: https://doi.org/10.2760/446145

Sala S, Crenna E, Secchi M, Sanyé-Mengual E (2020) Environmental sustainability of European production and consumption assessed against planetary boundaries. J Environ Manag 269:110686. https://doi.org/10.1016/j.jenvman.2020.110686

Sandin G, Peters GM, Svanström M (2015) Using the planetary boundaries framework for setting impact-reduction targets in LCA contexts. Int J Life Cycle Assess 20:1684-1700. https://doi.org/10. 1007/s11367-015-0984-6

Steen B, Arvidsson P, Nobel Gunnar Borg A, et al. (1999a) A systematic approach to environmental priority strategies in product development (EPS). Version 2000 - General system characteristics. Centre for Environmental Assessment of Products and Material Systems. Chalmers University of Technology, Technical Environmental Planning

Steen B, Arvidsson P, Nobel Gunnar Borg A et al (1999b) A systematic approach to environmental priority strategies in product development (EPS). Version 2000 - Models and data of the default method. Centre for Environmental Assessment of Products and Material Systems. Chalmers University of Technology, Technical Environmental Planning, Gothenburg

Steffen W, Richardson K, Rockstrom J et al (2015) Planetary boundaries: guiding human development on a changing planet. Science 347(80): 1259855. https://doi.org/10.1126/science.1259855

thinkstep (2019) Software: GaBi software. In: Version 9.2.0.58. http:// www.gabi-software.com/international/software/. Accessed 30 May 2017

Tuomisto HL, Hodge ID, Riordan P, MacDonald DW (2012) Exploring a safe operating approach to weighting in life cycle impact assessment - a case study of organic, conventional and integrated farming systems. J Clean Prod 37:147-153. https://doi.org/10.1016/j.jclepro. 2012.06.025

U.S. Geological Survey (2020) 2017 minerals yearbook. Aluminium (advance release). U.S. Geological Survey

UNEP (2016) Handbook for the Montreal protocol on substances that deplete the ozone layer. Tenth edition (2016). Secretariat for the Vienna convention for the protection of the ozone layer \& the Montreal protocol on substances that deplete the ozone layer. United Nations Environment Programme, Nairobi 
UNFCCC (2020) Nationally determined contributions. NDC Registery. In: United NationsFramework Conv. Clim. Chang. https://www4. unfccc.int/sites/ndcstaging/Pages/Home.aspx. Accessed 4 Apr 2020

United Nations (2015) Sustainable development goals. https://sdgs.un. org/. Accessed 25 Sep 2020

Vargas-Gonzalez M, Witte F, Martz P, Gilbert L, Humbert S, Jolliet O, van Zelm R, L'Haridon J (2019) Operational life cycle impact assessment weighting factors based on planetary boundaries: applied to cosmetic products. Ecol Indic 107:105498. https://doi.org/10. 1016/j.ecolind.2019.105498

Verones F, Bare J, Bulle C, Frischknecht R, Hauschild M, Hellweg S, Henderson A, Jolliet O, Laurent A, Liao X, Lindner JP, Maia de Souza D, Michelsen O, Patouillard L, Pfister S, Posthuma L, Prado V, Ridoutt B, Rosenbaum RK, Sala S, Ugaya C, Vieira M, Fantke P (2017) LCIA framework and cross-cutting issues guidance within the UNEP-SETAC Life Cycle Initiative. J Clean Prod 161:957-967. https://doi.org/10.1016/J.JCLEPRO.2017.05.206
Weidema BP (2009) Using the budget constraint to monetarise impact assessment results. Ecol Econ 68:1591-1598. https://doi.org/10. 1016/j.ecolecon.2008.01.019

Weidema B, Goedkoop M, Meijer E, Harmens R (2020) LCA-based assessment of the Sustainable Development Goals

Worldsteel (2016) World Steel in Figures 2016. World Steel Association, Brussels, Belgium

Worldsteel (2018) Life Cycle Inventory study report. Brussels, Belgium WRI (2020) CAIT climate data explorer. In: World Resour. Inst. . CAIT Hist. - Explor. Hist. Greenh. Gas Emiss. https://cait2.wri.org/. Accessed 6 Apr 2020

Zanghelini GM, Cherubini E, Soares SR (2018) How Multi-Criteria Decision Analysis (MCDA) is aiding Life Cycle Assessment (LCA) in results interpretation. J Clean Prod 172:609-622. doi: 10.1016/j.jclepro.2017.10.230

Publisher's note Springer Nature remains neutral with regard to jurisdictional claims in published maps and institutional affiliations. 